\title{
DIC-hole drilling method for in-situ residual stress measurement
}

\author{
Yang Peng ${ }^{l}$, Jun Zhao ${ }^{l}$, Lan-shu Chen ${ }^{l, 2}$, and Jun Dong ${ }^{1 *}$ \\ ${ }^{1}$ College of Civil Engineering, Nanjing Tech University, Nanjing, Jiangsu 211816, China \\ ${ }^{2}$ Shanghai CSCEC Dongfu Investment Development CO., LTD., Shanghai 200122, China
}

\begin{abstract}
Residual stress measurement carries an important significance in ensuring safety and reliability of steel structures. In order to simplify the measurement procedure and enhance flexibility of the conventional hole drilling method to adopt in in-situ residual stress measurement, digital image correlation (DIC) is applied to measure the displacement field caused by the localized stress relief associated due to hole drilling. It is referred to as DIC-hole drilling method. The residual stress theoretical expressions of the DIC-hole drilling method are discussed. The requirements of drilling device, camera and lens are determined by accounting for the accuracy of the in-situ residual stress measurement. A benchmark experiment by using steel beam specimens is developed to verify the feasibility and reliability of DIC-hole drilling method. Test data are compared with theoretical calculations and FEM results. The comparison indicates the DIC-hole drilling method has enough accuracy for the in-situ residual stress measurement. The displacement field in the regions centred at 2 to 2.5 times drilling hole radius far from the hole is proposed for the accurate residual stress measurement.
\end{abstract}

\section{Introduction}

The techniques of destructive detection and nondestructive detection to detect residual stress have been widely accepted[1]. Although the theoretical background is perfect, the destructive detection method causes great damage to the tested components. Nondestructive method has higher accuracy[2]. However, the testing conditions are harsh, and set up equipment in the field is difficult, it is unsuitable for in-situ rapid detection[3]. In order to realize the quick detection of residual stress in the field, the DIC-hole drilling method for in-situ measurement has been put forward.
The measurement of residual stress using optical techniques has been proposed by several authors in past years. McGinnis et al. proposed a DIC hole drilling method to detect residual stress[4]. Nelson et al. used the commercial ARAMIS image processing system to analyze the experimental error of DIC-hole drilling method[5]. Lord et al. used the 2D-DIC system to measure the releasing strain after drilling the blind hole to detect the residual stress of the specimen[6]. The results are similar to those of the blind hole method. Jianxin Gao and Haixia Shang studied a new method based on DIC-hole drilling method was used to calculate

"Corresponding author: dongjun@,njtech.edu.cn 
the residual stress directly. The residual stress before releasing is calculated directly as a variable[7]. Schajer et al. introduced the artifact correction algorithm of interference method into DIC-hole drilling method, and verified the applicability of the modified algorithm by FIB-SEM test[8].

In order to improve the limitation of the existing methods, it is urgent to study the in-situ application of DIC-hole drilling method. DIC method can be used to record the images before and after drilling, and the full field displacement can be calculated by these images. The DIC method is not sensitive to vibration, and does not need vibration isolation device. It can work under ordinary white light conditions and is suitable for rough surface. In terms of accuracy control, the existing research of DIC-hole drilling method only stays in the verification stage, and lacks a systematic evaluation of its accuracy[9]. Therefore, using DIC method to develop an economical, portable, accurate and real-time in-situ residual stress detection method is significant.

\section{DIC hole-drilling method for in-situ residual stress}

\subsection{Calculation principle}

The residual stress of blind-hole method is calculated by measuring the strain after releasing stress. However, the accuracy of DIC measurement is lower than that of releasing displacement, so it is necessary to reestablish the method. A schematic diagram of the numerical calculation method is shown in Figure 1[10], which directly calculates the residual stress of the measuring point by displacement measurement. $U_{1}, U_{2}$ and $U_{3}$ are $0^{\circ}, 45^{\circ}$ and $90^{\circ}$ respectively, and the radius is $r$ ( $r$ is larger than the aperture $0.75 \mathrm{~mm}$ ). The corresponding formula are formula (1) and formula (2).

$$
\left[\begin{array}{l}
U_{1}(r, \varphi) \\
U_{2}(r, \varphi) \\
U_{3}(r, \varphi)
\end{array}\right]=\left[\begin{array}{ccc}
A(r) & B(r) & 0 \\
A(r) & 0 & 2 B(r) \\
A(r) & -B(r) & 0
\end{array}\right]\left[\begin{array}{c}
P \\
Q \\
T
\end{array}\right]
$$

Where,

$$
\left\{\begin{array}{l}
P=\sigma_{x}(\varphi)+\sigma_{y}(\varphi) \\
Q=\sigma_{x}(\varphi)-\sigma_{y}(\varphi) \\
T=2 \tau_{x y}(\varphi)
\end{array}\right.
$$

In the formula, $r$ is the measuring line radius of displacement ( $r$ is greater than $\left.r_{0}\right) . U_{1}\left(r, 0^{\circ}\right), U_{2}\left(r, 45^{\circ}\right)$ and $U_{3}\left(r, 90^{\circ}\right)$ are relative displacements between two ends of the measuring line after releasing stress. $\varphi$ is displacement measuring line rotation angle $\left(0^{\circ}<\varphi<180^{\circ}\right)$. $\sigma_{x}(\varphi), \sigma_{y}(\varphi), \tau_{x y}(\varphi)$ are all the stress components of the measuring points before releasing stress. $A(r)$ and $B(r)$ are calibrated releasing coefficients when the measured line radius is $r$.

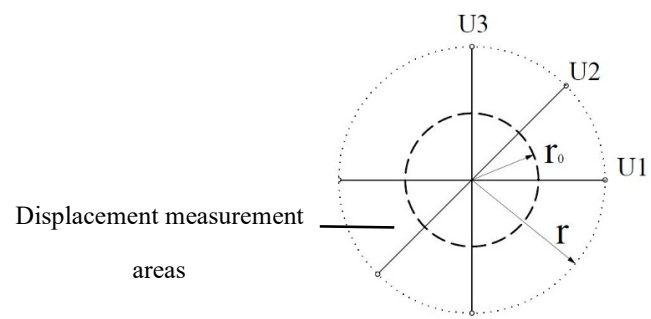

Fig. 1. Calculation principles of DIC-hole drilling method

In order to reduce the systematic errors and accidental errors, the residual stress can be calculated by using multiple groups of displacement data[11]. Taking the average value of these data for correction can effectively reduce these errors.

\subsection{Selection of device configuration}

In order to ensure the working distance of the DIC binocular camera and prevent drilling device from scratching the random speckles, the JHZK type precision residual stress drilling device is adopted, and the aperture is $D=1.5 \mathrm{~mm}$. The field range is $30 \mathrm{~cm} \times 30 \mathrm{~cm}$ centered on blind hole to meet the requirement of displacement measurement accuracy.

The experiment uses the VIC-3D system developed by CSI company, set up the VIC-3D system in the laboratory, as shown in Figure 2.

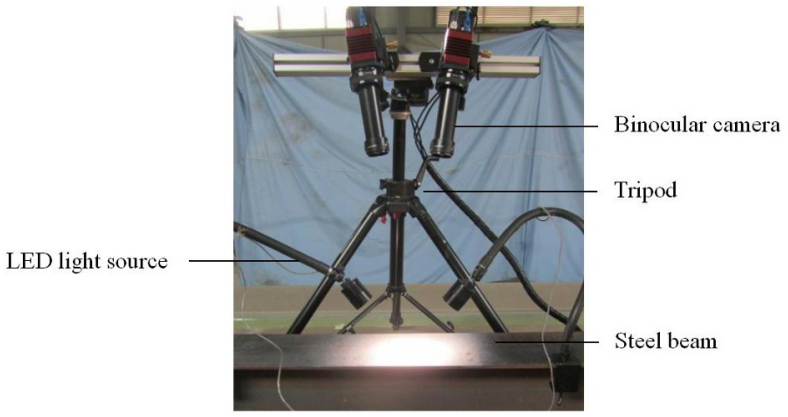

Fig. 2. VIC-3D System

\subsection{Testing procedure}

Before the testing procedure of the experiment, a 
four-point bending rebound test of hot rolled steel beam is designed to calculate the rebound stress distribution. As shown in Figure 3, the theoretical value of residual stress can be calculated. The measuring points are separated by $30 \mathrm{~mm}$ along the high direction of the beam, selecting point 1 to discuss, the distance from the lower flange is $84.5 \mathrm{~mm}$.

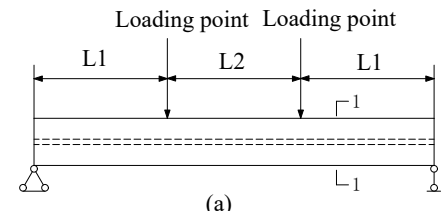

(a)

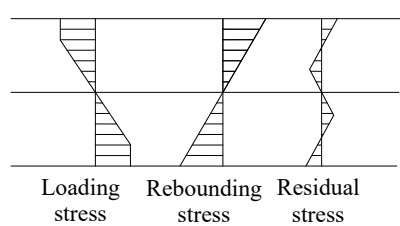

(c)

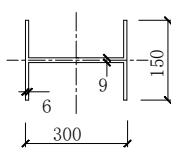

(b)
Fig.3. Theoretical calculation of residual stress

(a) Loading method (b) Steel beam section 1-1

(c)Stress superposition

In-situ testing procedure as follows:

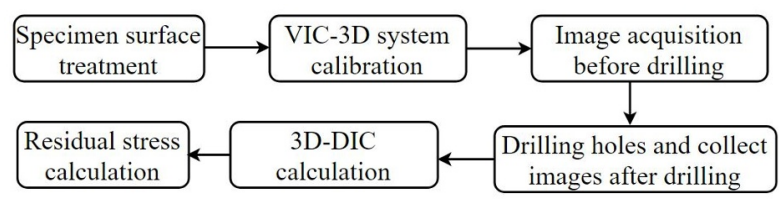

Fig.4. Testing procedure

Here, in particular, need to note that the image after drilling is taken as the center of the blind hole and the coordinate system is established to determine the angle and measuring radius.

\subsection{Finite element calibration of releasing}

\section{coefficient}

ABAQUS is used to calibrate the releasing coefficient $A(r)$ and $B(r)$. Because of the symmetry, the $1 / 4$ part of the specimen is centered on the center of the blind hole to establish the model. The model adopts Solid45 unit and $1 / 4$ part size is $50 \mathrm{~mm} \times 25 \mathrm{~mm} \times 9 \mathrm{~mm}$. The diameter of the hole $D_{0}$ is $1.5 \mathrm{~mm}$ and the depth $h$ is $2 \mathrm{~mm}$, which is the same as that of the test. Mesh grid division of calibrated releasing coefficient is shown in Figure 5.

The load level in finite element method is divided into 18 steps. After the solution, the relative displacement $U_{1}(r, 0)$ and $U_{2}(r, 0)$ can be extracted before and after drilling at each load level respectively, and the value of the releasing coefficient $A(r), B(r)$ can be obtained under each load level, as shown in Table 1.

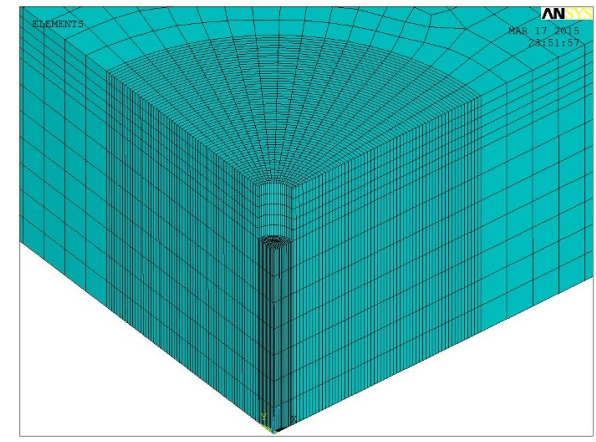

Fig. 5. Mesh grid division of FEM

Table 1. Coefficients of A(r) and B(r) under different stress levels

\begin{tabular}{ccccc}
\hline $\begin{array}{c}\text { Stress } \\
\text { level/MPa }\end{array}$ & $\mathrm{A}(\mathrm{r})$ & $\mathrm{B}(\mathrm{r})$ & $\mathrm{c} r=1.875 \mathrm{~mm}$ \\
\hline 20 & $2.56 \mathrm{E}-6$ & $5.5 \mathrm{E}-6$ & $2.03 \mathrm{E}-06$ & $4.28 \mathrm{E}-06$ \\
40 & $2.56 \mathrm{E}-6$ & $5.5 \mathrm{E}-6$ & $2.03 \mathrm{E}-06$ & $4.28 \mathrm{E}-06$ \\
60 & $2.56 \mathrm{E}-6$ & $5.50 \mathrm{E}-6$ & $2.03 \mathrm{E}-06$ & $4.28 \mathrm{E}-06$ \\
80 & $2.56 \mathrm{E}-6$ & $5.50 \mathrm{E}-6$ & $2.03 \mathrm{E}-06$ & $4.28 \mathrm{E}-06$ \\
100 & $2.56 \mathrm{E}-6$ & $5.51 \mathrm{E}-06$ & $2.03 \mathrm{E}-06$ & $4.28 \mathrm{E}-06$ \\
120 & $2.56 \mathrm{E}-6$ & $5.50 \mathrm{E}-6$ & $2.03 \mathrm{E}-06$ & $4.28 \mathrm{E}-06$ \\
140 & $2.56 \mathrm{E}-6$ & $5.51 \mathrm{E}-06$ & $2.03 \mathrm{E}-06$ & $4.28 \mathrm{E}-06$ \\
160 & $2.57 \mathrm{E}-6$ & $5.51 \mathrm{E}-06$ & $2.03 \mathrm{E}-06$ & $4.28 \mathrm{E}-06$ \\
180 & $2.61 \mathrm{E}-6$ & $5.51 \mathrm{E}-06$ & $2.06 \mathrm{E}-06$ & $4.29 \mathrm{E}-06$ \\
200 & $2.68 \mathrm{E}-6$ & $5.53 \mathrm{E}-06$ & $2.11 \mathrm{E}-06$ & $4.31 \mathrm{E}-06$ \\
220 & $2.78 \mathrm{E}-6$ & $5.55 \mathrm{E}-06$ & $2.18 \mathrm{E}-06$ & $4.35 \mathrm{E}-06$
\end{tabular}




\begin{tabular}{lllll}
240 & $2.90 \mathrm{E}-6$ & $5.59 \mathrm{E}-06$ & $2.27 \mathrm{E}-06$ & $4.39 \mathrm{E}-06$ \\
260 & $3.06 \mathrm{E}-6$ & $5.63 \mathrm{E}-06$ & $2.38 \mathrm{E}-06$ & $4.45 \mathrm{E}-06$ \\
280 & $3.26 \mathrm{E}-6$ & $5.69 \mathrm{E}-06$ & $2.54 \mathrm{E}-06$ & $4.53 \mathrm{E}-06$ \\
300 & $3.62 \mathrm{E}-6$ & $5.72 \mathrm{E}-06$ & $2.80 \mathrm{E}-06$ & $4.61 \mathrm{E}-06$ \\
320 & $4.20 \mathrm{E}-6$ & $5.61 \mathrm{E}-06$ & $3.25 \mathrm{E}-06$ & $4.61 \mathrm{E}-06$ \\
340 & $5.05 \mathrm{E}-6$ & $5.42 \mathrm{E}-06$ & $4.02 \mathrm{E}-06$ & $4.46 \mathrm{E}-06$ \\
360 & $6.20 \mathrm{E}-6$ & $5.39 \mathrm{E}-06$ & $5.17 \mathrm{E}-06$ & $4.39 \mathrm{E}-06$ \\
\hline
\end{tabular}

\section{Results and discussions}

Displacement data of point 1 is detected by DIC-hole drilling method. And $U_{1}, U_{2}$ and $U_{3}$ of point 1 measured by DIC-hole drilling method are shown in Table 2.

Table 2. Displacement measurement in point 1

\begin{tabular}{|c|c|c|}
\hline $\begin{array}{c}\text { Angle } \\
\text { between } \\
\text { measurement } \\
\text { line U1 and X } \\
\text { axis } /^{\circ}\end{array}$ & $\begin{array}{l}\text { Measuring } \\
\text { line }\end{array}$ & $\begin{array}{l}\text { Displacement } \\
\text { measurement/u }\end{array}$ \\
\hline \multirow{3}{*}{0} & U1 & $-5.34 \mathrm{E}-04$ \\
\hline & U2 & $-2.62 \mathrm{E}-04$ \\
\hline & U3 & $1.18 \mathrm{E}-04$ \\
\hline \multirow{3}{*}{15} & U1 & $-4.68 \mathrm{E}-04$ \\
\hline & U2 & $-1.25 \mathrm{E}-04$ \\
\hline & U3 & $1.08 \mathrm{E}-04$ \\
\hline \multirow{3}{*}{30} & U1 & $-3.22 \mathrm{E}-04$ \\
\hline & $\mathrm{U} 2$ & $3.20 \mathrm{E}-04$ \\
\hline & U3 & $1.41 \mathrm{E}-04$ \\
\hline \multirow{3}{*}{45} & U1 & $-2.62 \mathrm{E}-04$ \\
\hline & U2 & $1.18 \mathrm{E}-04$ \\
\hline & U3 & $-1.89 \mathrm{E}-04$ \\
\hline \multirow{3}{*}{60} & U1 & $-1.25 \mathrm{E}-04$ \\
\hline & U2 & $1.08 \mathrm{E}-04$ \\
\hline & U3 & $-4.62 \mathrm{E}-04$ \\
\hline \multirow{3}{*}{75} & U1 & $3.20 \mathrm{E}-04$ \\
\hline & U2 & $1.41 \mathrm{E}-04$ \\
\hline & U3 & $-5.47 \mathrm{E}-04$ \\
\hline
\end{tabular}

According to formula (1) (2) and displacement, the residual stress can be calculated. Then compared with theoretical value, as shown in Table 3. When the radius of measuring circle is $2 \sim 2.5$ times the radius of the blind hole, the dispersion of $\sigma_{x}(\varphi)$ is larger at the same radius of the measured circle and $\sigma_{x}(\varphi)$ is relatively stable when the mean $\sigma_{x}(\varphi)$ is taken from the two groups of $\sigma_{x}(\varphi)$. The accuracy of measuring circle radius is high in the range of $2 \sim 2.5$ times the radius of the blind hole, and the error is about $10 \%$. If the radius is too small, the speckle around the hole will be damaged, which is not conducive to observation. When the radius is too large, the point displacement far away from the hole cannot be observed because of the nonlinear attenuation of displacement, so the radius must be controlled within a reasonable range.

Table 3. Comparison between stress at different angles and

\begin{tabular}{ccc}
\multicolumn{3}{c}{ finite element results in point 1} \\
\hline Angle $/ 0$ & \multicolumn{2}{c}{ Measuring stress $/ \mathrm{MPa}$} \\
& $r=1.5 \mathrm{~mm}$ & $r=1.875 \mathrm{~mm}$ \\
\hline$\sigma_{x}(0)$ & -210.9 & -207.9 \\
$\sigma_{x}(15)$ & -244.4 & -198.9 \\
$\sigma_{x}(30)$ & -286.7 & -153.2 \\
$\sigma_{x}(45)$ & -282.1 & -221.1 \\
$\sigma_{x}(60)$ & -215.0 & -333.8 \\
$\sigma_{x}(75)$ & -114.9 & -164.2 \\
Mean value & -225.7 & -213.2 \\
Theoretical value/MPa & -205.3 & -205.3 \\
Relative error/\% & 9.9 & 3.8 \\
\hline
\end{tabular}

\section{Conclusion}

(1) DIC-hole drilling method is simple in surface treatment and fast in operation, so it is convenient for commercialization of equipment and software.

(2) DIC-hole drilling method with full displacement field data can reduce the influence of accidental error on detection results.

(3) The accuracy of measuring circle is high in the range of $r=2 r_{\mathrm{o}} \sim 2.5 r_{\mathrm{o}}$ by DIC-hole drilling method.

\section{Acknowledgements}

The authors wish to thank the Natural Science 
Foundation of China for financially supporting the research in the paper through the grant No. 51408307.

\section{Reference}

1. Wang Jianhua, Lu Tao. Some discussions on principle of causing and relieving welding residual stress [J]. Transactions of China Welding Institution, 2002, 23 (3): 75-79

2. Zhu GuoMing, Kang Yonglin, Ma Guangting, et al. Research of residual stress in hot rolled large size H-beams [J]. Journal of Plasticity Engineering, 2010, 17 (5): 88-92

3. Quach Waimeng, Teng Jingguang, Chung Kwokfai. Finite element predictions of residual stresses in cold-formed steel sections [J]. Progress in Steel Building Structures, 2007. 9 (3): 26-32

4. McGinnis M J, Pessiki S, Turker H. Application of three dimensional digital image correlation to the core-drilling method $[\mathrm{J}]$. Experimental Mechanics, 2005, 45(4): 359-367.

5. Nelson D V, Makino A, Schmidt T. Residual stress determination using hole drilling and 3D image correlation [J]. Experimental Mechanics, 2006, 46(1): 31-38.

6. Lord J D, Penn D, Whitehead P. The application of digital image correlation for measuring residual stress by incremental hole drilling [J]. Applied Mechanics, 2008, 1314: 65-73.

7. Gao J, Shang H. Deformation-pattern-based digital image correlation method and its application to residual stress measurement $[\mathrm{J}]$. Applied Optics, 2009, 48: 1371-1381.

8. Schajer G S, Winiarski B, Withers P J. Hole-Drilling Residual Stress Measurement with Artifact Correction Using Full-Field DIC [J]. Experimental Mechanics, 2013, 53: 255-265.

9. Zhu Jianguo, Li Yanjie. Fabrication and Applications of microscale deformation carrier with FIB [J]. Experimental Mechanics, 2013, 28(2): 151-157.

10. Winiarski B, Withers $\mathrm{P}$ J. Micron-scale residual stress measurement by micro-hole drilling image correlation [J]. Experimental Mechanics, 2012, 52 (4): 417-428

11. Huang Baofu, Zhou Futian, Zhangfengfa, et al. Design and application of weld joints residual stress MMM testing system [J]. Refining and Chemical Industry, 2012, 23 (1): 7-9 